Article

\title{
Predicting the Global Potential Distribution of Four Endangered Panax Species in Middle-and Low-Latitude Regions of China by the Geographic Information System for Global Medicinal Plants (GMPGIS)
}

\author{
Zhixia Du ${ }^{1}$, Jie $\mathrm{Wu}^{2}$, Xiangxiao Meng ${ }^{2}$, Jinhua $\mathrm{Li}^{1}$ and Linfang Huang ${ }^{1, *}$ \\ 1 Institute of Medicinal Plant Development (IMPLAD), Chinese Academy of Medical Sciences (CAMS), \\ Peking Union Medical College (PUMC), Beijing 100193, China; zxdu712@126.com (Z.D.); \\ jinhuali108@126.com (J.L.) \\ 2 Institute of Chinese Materia Medica, China Academy of Chinese Medical Sciences, Beijing 100700, China; \\ jwu1986@icmm.ac.cn (J.W.); xxmeng@icmm.ac.cn (X.M.) \\ * Correspondence: lfhuang@implad.ac.cn; Tel.: +86-10-5783-3197
}

Received: 21 August 2017; Accepted: 25 September 2017; Published: 28 September 2017

\begin{abstract}
Global biodiversity is strongly influenced by the decrease in endangered biological species. Predicting the distribution of endangered medicinal plants is necessary for resource conservation. A spatial distribution model-geographic information system for global medicinal plants (GMPGIS) - is used to predict the global potential suitable distribution of four endangered Panax species, including Panax japonicas (T. Nees) C. A. Meyer and Panax japonicas var. major (Burkill) C. Y. Wu \& K. M. Feng distributed in low- and middle-latitude, Panax zingiberensis C. Y. Wu \& K. M. Feng and Panax stipuleanatus C. T. Tsai \& K. M. Feng in low-latitude regions of China based on seven bioclimatic variables and 600 occurrence points. Results indicate that areas of $P$. japonicus and $P$. japonicus var. major are $266.29 \times 10^{5}$ and $77.5 \times 10^{5} \mathrm{~km}^{2}$, respectively, which are mainly distributed in China and America. By contrast, the areas of P. zingiberensis and P. stipuleanatus are $5.09 \times 10^{5}$ and $2.05 \times 10^{5} \mathrm{~km}^{2}$, respectively, which are mainly distributed in Brazil and China. P. japonicus has the widest distribution among the four species. The data also indicate that the mean temperature of coldest quarter is the most critical factor. This scientific prediction can be used as reference for resource conservation of endangered plants and as a guide to search for endangered species in previously unknown areas.
\end{abstract}

Keywords: Panax; global potential distribution; geographic information system for global medicinal plants (GMPGIS)

\section{Introduction}

Panax (Araliaceae) species are the important medicinal resources in the world. Panax ginseng and Panax quinquefolium are distributed at high-latitude regions. By contrast, some endangered Panax species such as P. japonicus and P. japonicus var. major found in middle- and low-latitude regions, have been recorded in the Chinese Pharmacopoeia. P. japonicus is known as "the king of herbs" in Chinese folk, and has been included in the Japanese Pharmacopoeia as a traditional Japanese medicine. P. zingiberensis and P. stipuleanatus distributed in low-latitude regions are also used widely as traditional ethnic medicines. Panax species are popular due to their potential medicinal properties [1-4], such as anti-fatigue, anti-tumor, anti-thrombotic, anti-inflammatory, anti-oxidative, and immune-enhancing effects and thus have a substantial market demand worldwide [5-7]. 
However, their resources are gradually declining due to excessive harvesting and lack of environmental protection. Therefore, predicting the distribution of plants is necessary for their conservation [8].

With the development of network technology, a distribution prediction model has become one of the common methods in biodiversity conservation, such as MaxEnt (Maximum Entropy), Random Forset [9-13], GMPGIS (the geographic information system for global medicinal plants) [14-16]. The GMPGIS selected seven key ecological factors (especially related to its growth and accumulation of secondary metabolism) for medicinal plants according to biological characteristics of medicinal plants, statistics, ecology, botany, and related literatures, and experience. In this research, the global potential distribution of four endangered Panax species found in middle- and low-latitude regions was predicted by using GMPGIS. The GMPGIS model has been created by the Institute of Chinese Materia Medica in order to predict the distribution of medicinal plants [17] using environment databases such as WorldClim, CliMond, and HWSD. This model has been used for introduction and conservation of Panax ginseng C. A. Mey and Panax notoginseng (Burk.) F. H. Chen [18]. By combining the climate and soil factors to explore areas that have the most similar ecological factors, we can determine the suitable environment for medicinal plants to scientifically protect and cultivate the endangered plants. MaxEnt is also widely used to predict species distribution [19-28]. Potential suitable distribution plays an important role in resource protection and cultivation of endangered plants. We studied and compared the differences between GMPGIS and MaxEnt and found that GMPGIS shows higher precision than MaxEnt. In this research, GMPGIS was used to analyze the plant habitats, whereas MaxEnt was used for supplementary information.

We used GMPGIS to scientifically predict the global distribution of four endangered Panax species based on the climate and soil factors. The global potential suitable distributions were mapped by excluding the unsuitable areas, such as lakes, rivers, and cities. This research aims to predict the global potential suitable distribution of four endangered Panax species and provide a scientific reference for protecting wild resources and breeding endangered plants.

\section{Results}

\subsection{Ecological Factors}

GMPGIS was used to extract the ecological factor data of collected sampling points (Figure 1 and Table 1), Panax zingiberensis and Panax stipuleanatus are distributed in low-latitude regions, which include China and Burma. Panax japonicus and Panax japonicus var. major are distributed in low and middle latitude regions. Figure 2 and Table 2 show the whole ecological factors range of each plant which plays an important role in cultivation. The contributions of each ecological factor were revealed by MaxEnt shown in Table 3, we found that the proportions of the mean temperature of the coldest quarter were $44.7 \%, 55.5 \%, 45.6 \%$, and $43.0 \%$ for P. japonicus var. major, P. japonicas, Panax zingiberensis, Panax stipuleanatus. The proportions of annual precipitation were $36.0 \%, 37.8 \%$, and $42.3 \%$ for P. japonicas, Panax zingiberensis, Panax stipuleanatus. This result provides a favorable condition for further analysis and experiment, and we can clearly understand the suitable range of climate factors and soil for these endangered medicinal plants.

Table 1. Global spatial distribution of sample points for four endangered Panax species.

\begin{tabular}{ccc}
\hline Latin Name of Species & Sampling Distribution & Sampling Points \\
\hline P. japonicus & $\begin{array}{c}\text { Global: China, Japan, North Korea } \\
\text { China: Yunnan, Guizhou, Sichuan, Hubei, etc. } \\
\text { China: Shaanxi, Sichuan, Yunan, Gansu, } \\
\text { Guizhou, etc. }\end{array}$ & 176 \\
P. japonicus var.major & $\begin{array}{c}\text { Global: China, Burma } \\
\text { China: Yunnan } \\
\text { Global: China, Burma } \\
\text { China: Yunnan }\end{array}$ & 102 \\
P. zingiberensis & Cipuleanatus & 101 \\
\hline
\end{tabular}




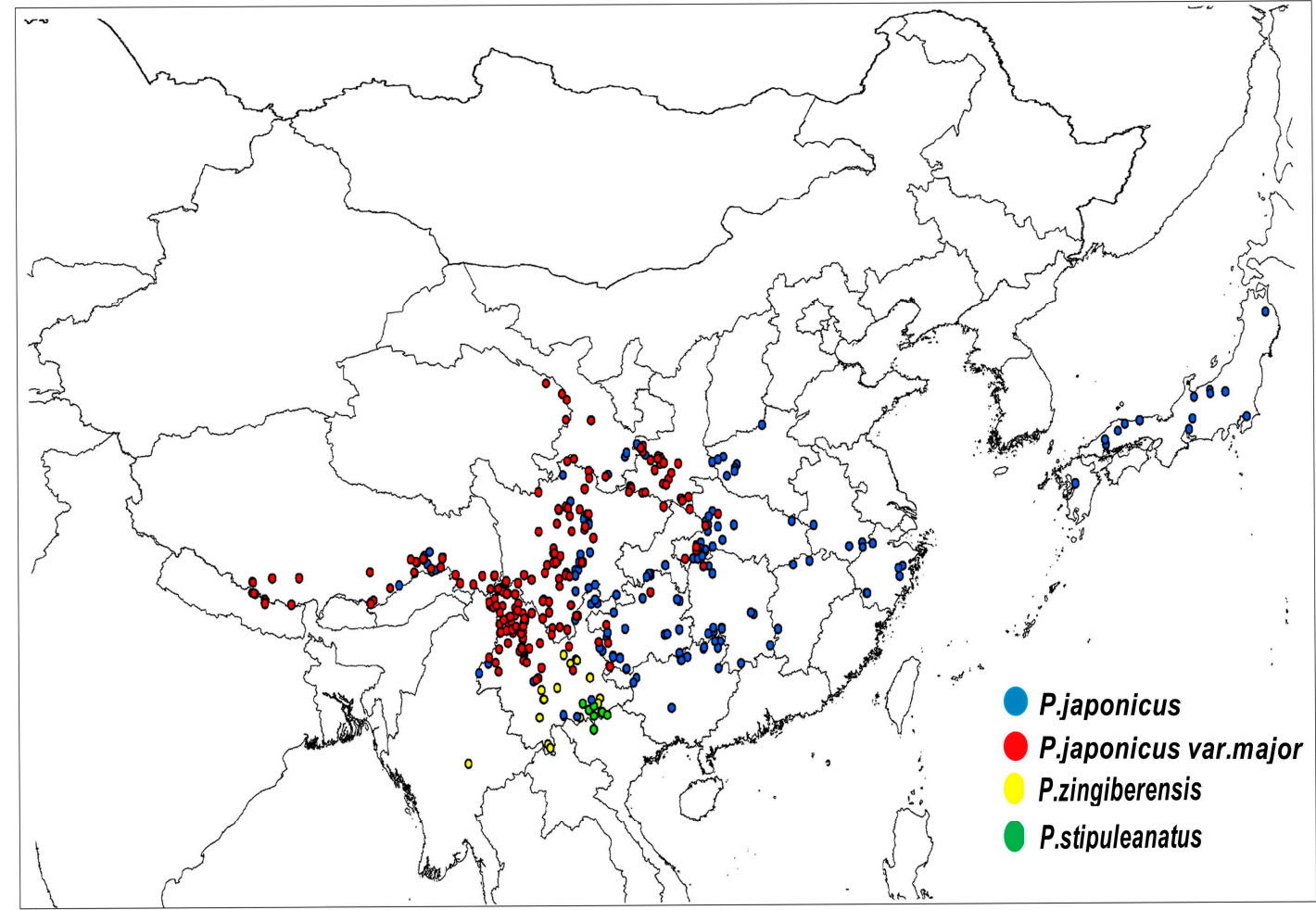

Figure 1. Global spatial distribution of sample points for four endangered Panax species, (blue) P. japonicas; (red) P. japonicus var. major; (yellow) P. zingiberensis; (green) P. stipuleanatus.

Table 2. The range of ecological factors for four endangered Panax species.

\begin{tabular}{|c|c|c|c|c|c|c|}
\hline $\begin{array}{l}\text { Latin Name } \\
\text { of Species }\end{array}$ & $\begin{array}{c}\text { Annual Mean } \\
\text { Temperature } /{ }^{\circ} \mathrm{C}\end{array}$ & $\begin{array}{c}\text { Mean Temperature } \\
\text { of Coldest } \\
\text { Quarter }{ }^{\circ} \mathrm{C}\end{array}$ & $\begin{array}{c}\text { Mean Temperature } \\
\text { of Warmest } \\
\text { Quarter } /{ }^{\circ} \mathrm{C}\end{array}$ & $\begin{array}{c}\text { Annual } \\
\text { Precipitation/mm }\end{array}$ & $\begin{array}{c}\text { Annual } \\
\text { Humidity } / \%\end{array}$ & $\begin{array}{l}\text { Annual Average } \\
\text { Radiation } / \mathbf{w} \cdot \mathbf{m}^{-2}\end{array}$ \\
\hline \multirow{2}{*}{ P. japonicus } & $2.6 \sim 22.3$ & $-7.0 \sim 14.3$ & $10.7 \sim 28.8$ & $539 \sim 2273$ & $49.4 \sim 75.5$ & $118.7 \sim 157.6$ \\
\hline & \multicolumn{6}{|c|}{ soil types: Lixisols, Arenosols, Chernozems, Luvisols, Ferralsols, Acrisols, Andosols, etc. } \\
\hline \multirow{2}{*}{$\begin{array}{l}\text { P. japonicus } \\
\text { var.major }\end{array}$} & $-8.6 \sim 20.5$ & $-17.5 \sim 14.7$ & $-1.9 \sim 26.7$ & $272 \sim 2562$ & $44.9 \sim 73.3$ & $118.3 \sim 157.9$ \\
\hline & \multicolumn{6}{|c|}{ soil types: Lixisols, Chernozems, Greyzems, Leptosols, Arenosols, etc. } \\
\hline \multirow{2}{*}{ P. zingiberensis } & $13 \sim 22.7$ & $6.9 \sim 18.0$ & $17.8 \sim 25.9$ & $957 \sim 1772$ & $54.1 \sim 75.3$ & $136.3 \sim 160.1$ \\
\hline & \multicolumn{6}{|c|}{ soil types: Acrisols, Arenosols, Arenosols, etc. } \\
\hline \multirow{2}{*}{ P. stipuleanatus } & $15 \sim 20.6$ & $8.8-14.9$ & $19.7 \sim 24.9$ & $888 \sim 2161$ & $61.2 \sim 76.4$ & $136.9 \sim 156.0$ \\
\hline & \multicolumn{6}{|c|}{ soil types: Acrisols, Arenosols, etc. } \\
\hline
\end{tabular}

Table 3. Contribution of ecological factors (\%) based on MaxEnt.

\begin{tabular}{ccccc}
\hline \multirow{2}{*}{ Variable } & \multicolumn{4}{c}{ Contribution (\%) } \\
\cline { 2 - 5 } & P. japonicus & P. japonicus var. major & P. zingiberensis & P. stipuleanatus \\
\hline Cold & 55.5 & 44.7 & 45.6 & 43.0 \\
Pre & 36.0 & 5.7 & 37.8 & 42.3 \\
Tem & 4.5 & 7.1 & 4.9 & 2.8 \\
Warm & 3.0 & 4.5 & 9.4 & 9.7 \\
Rad & 0.6 & 37.7 & 2.0 & 0.1 \\
hum & 0.4 & 2.4 & 0.3 & 2.0 \\
\hline
\end{tabular}

(Cold: mean temperature of coldest quarter, pre: annual precipitation, tem: annual mean temperature, warm: mean temperature of warmest quarter, rad: annual average radiation, hum: annual humidity). 

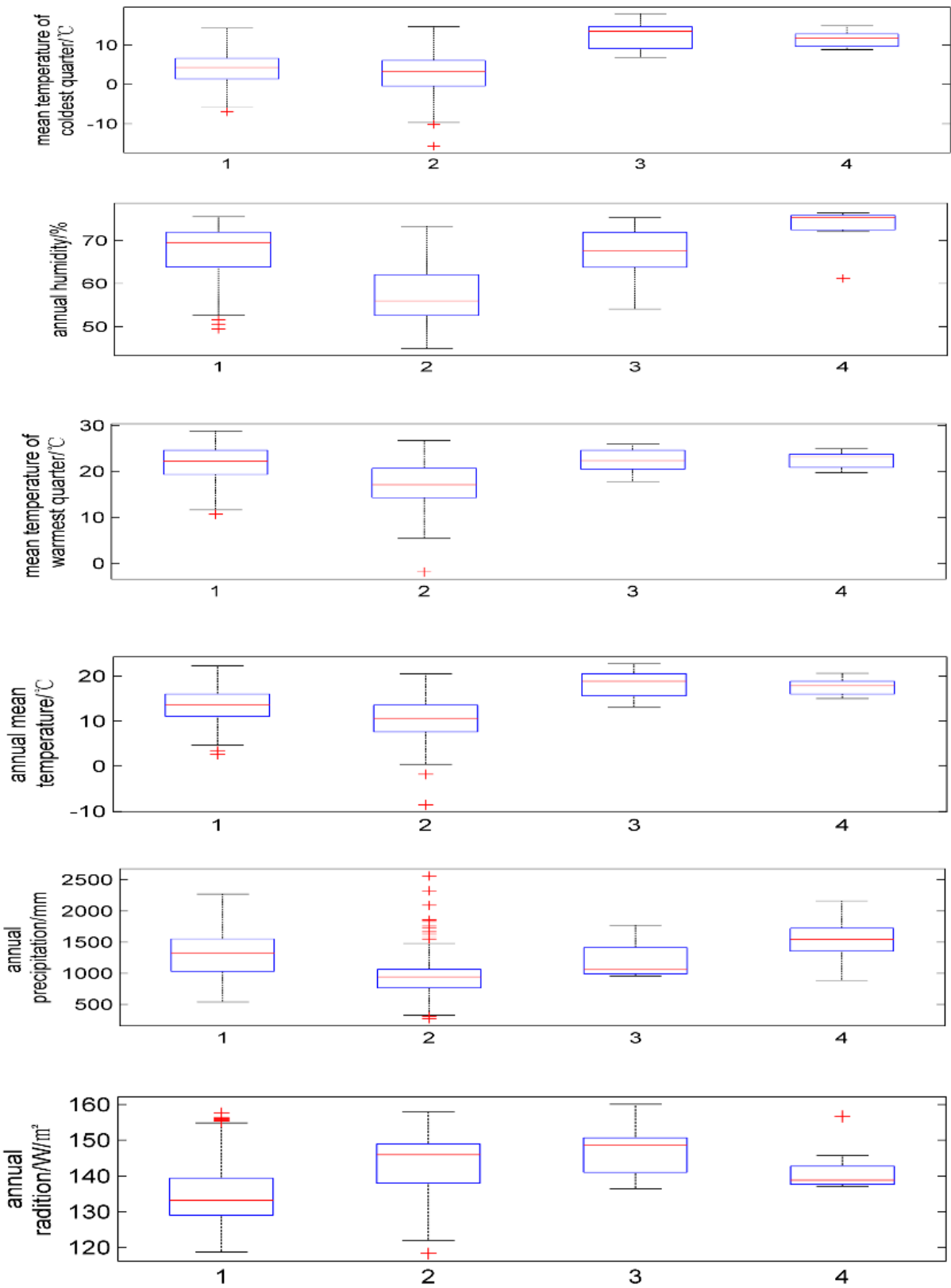

Figure 2. Boxplot of ecological factor of four endangered Panax species by MATLAB, ecological factor scope of P. japonicus and P. japonicus var. major are much broader(1: P. japonicas; 2: P. japonicus var. major; 3: P. zingiberensis; 4: P. stipuleanatus).

\subsection{Potential Distribution}

\subsubsection{Global Potential Distribution}

The potential distribution of endangered plants was influenced by the variation in the soil and climatic factors. Some environmental variables were also strongly correlated with the potential distributions.

(1) Potential distribution of P. japonicus: The global potential distribution of P. japonicus is obtained by GMPGIS based on the ecological factors and soil, the total area is $118.29 \times 10^{5} \mathrm{~km}^{2}$. P. japonicus is distributed mainly in North and South America, Asia, Europe, Oceania, and other regions (Figure 3A). The leading distribution areas are Southeast Asia and North America, which include 
China, Japan, South Korea, North Korea, the United States, and Canada. The top three distribution areas are China $\left(2662.98 \times 10^{3} \mathrm{~km}^{2}\right)$, United States $\left(2312.34 \times 10^{3} \mathrm{~km}^{2}\right)$, and France $\left(260.81 \times 10^{3} \mathrm{~km}^{2}\right)$ as shown in Figure 3B.

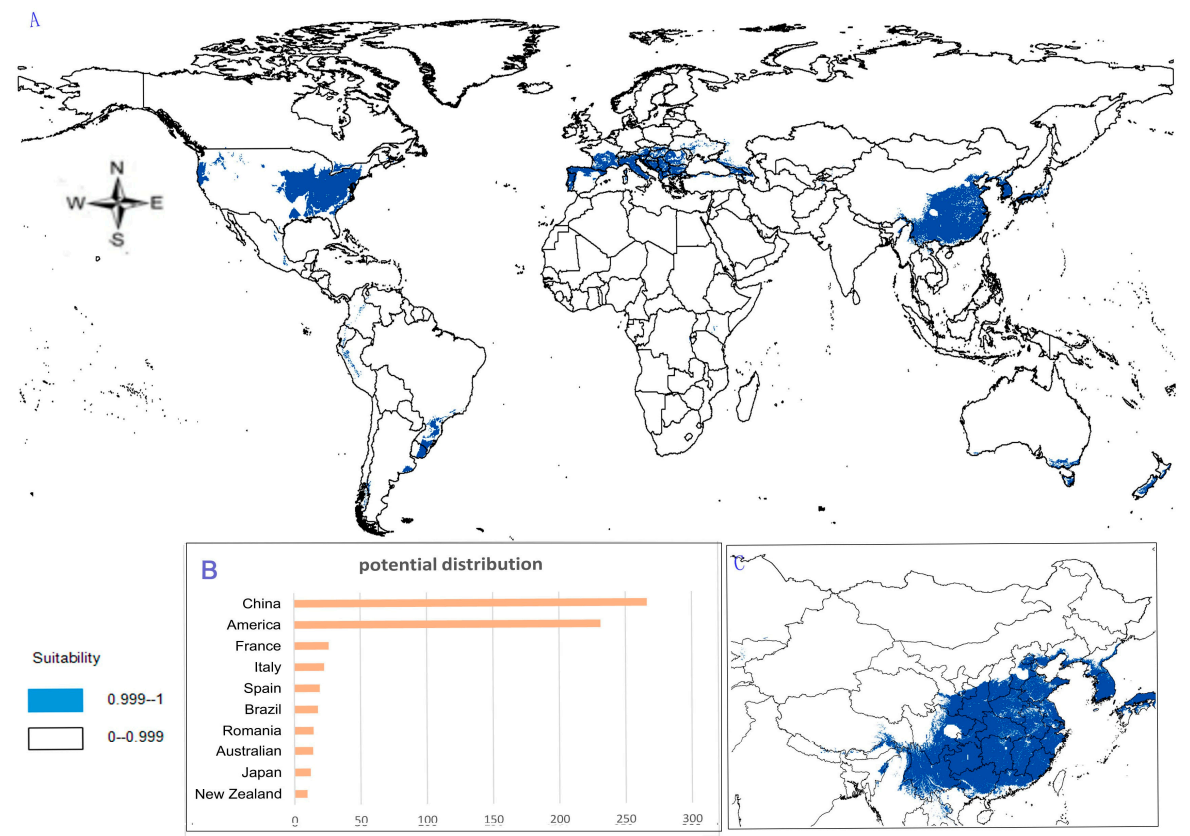

Figure 3. Spatial distribution map of potential suitable distribution for P. japonicus by GMPGIS. (A) Global potential distribution; (B) Global rank of the potential distribution area; (C) Chinese potential distribution.

(2) Potential distribution of P. japonicus var. major: The potential distribution regions for this plant are found in North America, Asia, and Europe (Figure 4A). The total global potential distribution area is $77.5 \times 10^{5} \mathrm{~km}^{2}$, and the top three distribution areas are the United States $\left(3438.73 \times 10^{3} \mathrm{~km}^{2}\right)$, China $\left(2986.11 \times 10^{3} \mathrm{~km}^{2}\right)$, and Russia $\left(861.09 \times 10^{3} \mathrm{~km}^{2}\right)$ (Figure 4B).

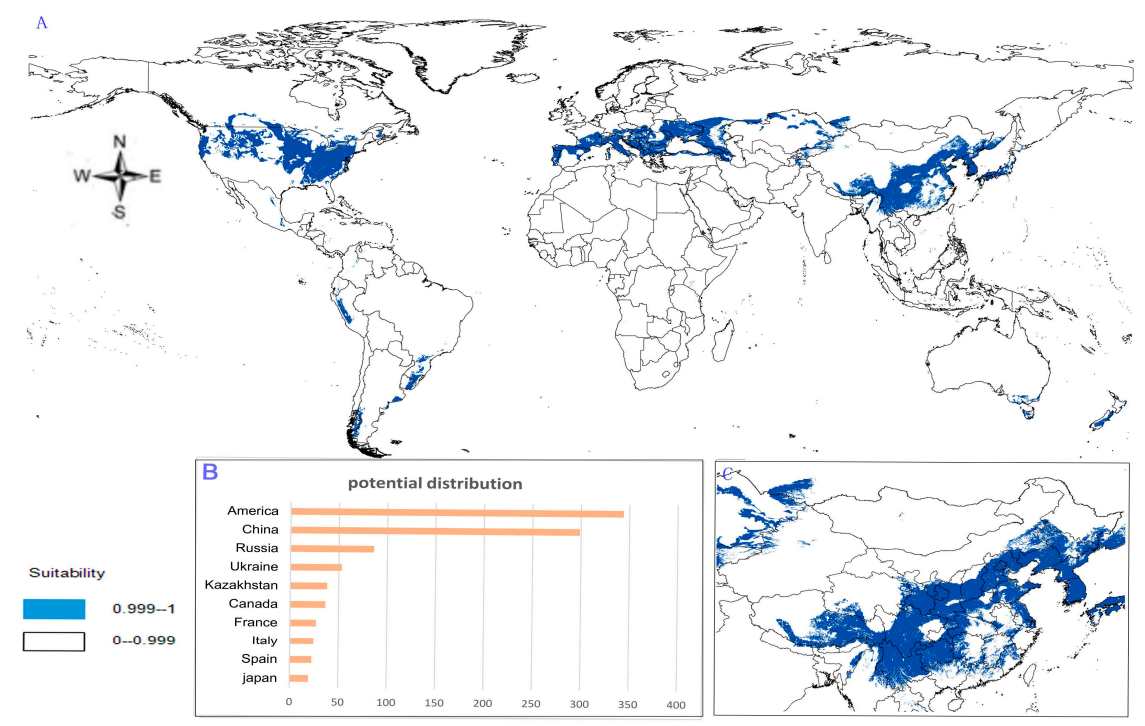

Figure 4. Spatial distribution map of potential suitable distribution for P. japonicus var. major by GMPGIS. (A) Global potential distribution; (B) Global rank of the potential distribution area; (C) Chinese potential distribution. 
(3) Potential distribution of $P$. zingiberensis: The global potential suitable distribution of $P$. zingiberensis is obtained by GMPGIS (Figure 5A). The map shows the limited distribution of this species, which is distributed in a small part of Asia and South America. The total global potential suitable distribution area is $5.09 \times 105 \mathrm{~km}^{2}$, the top three distribution areas are Brazil $\left(232.79 \times 10^{3} \mathrm{~km}^{2}\right)$, China $\left(166.71 \times 10^{3} \mathrm{~km}^{2}\right)$, and the United States $\left(39.58 \times 10^{3} \mathrm{~km}^{2}\right)$ shown in Figure $5 \mathrm{~B}$. Thus, the introduction and cultivation of $P$. zingiberensis should be prioritized in these countries and regions.

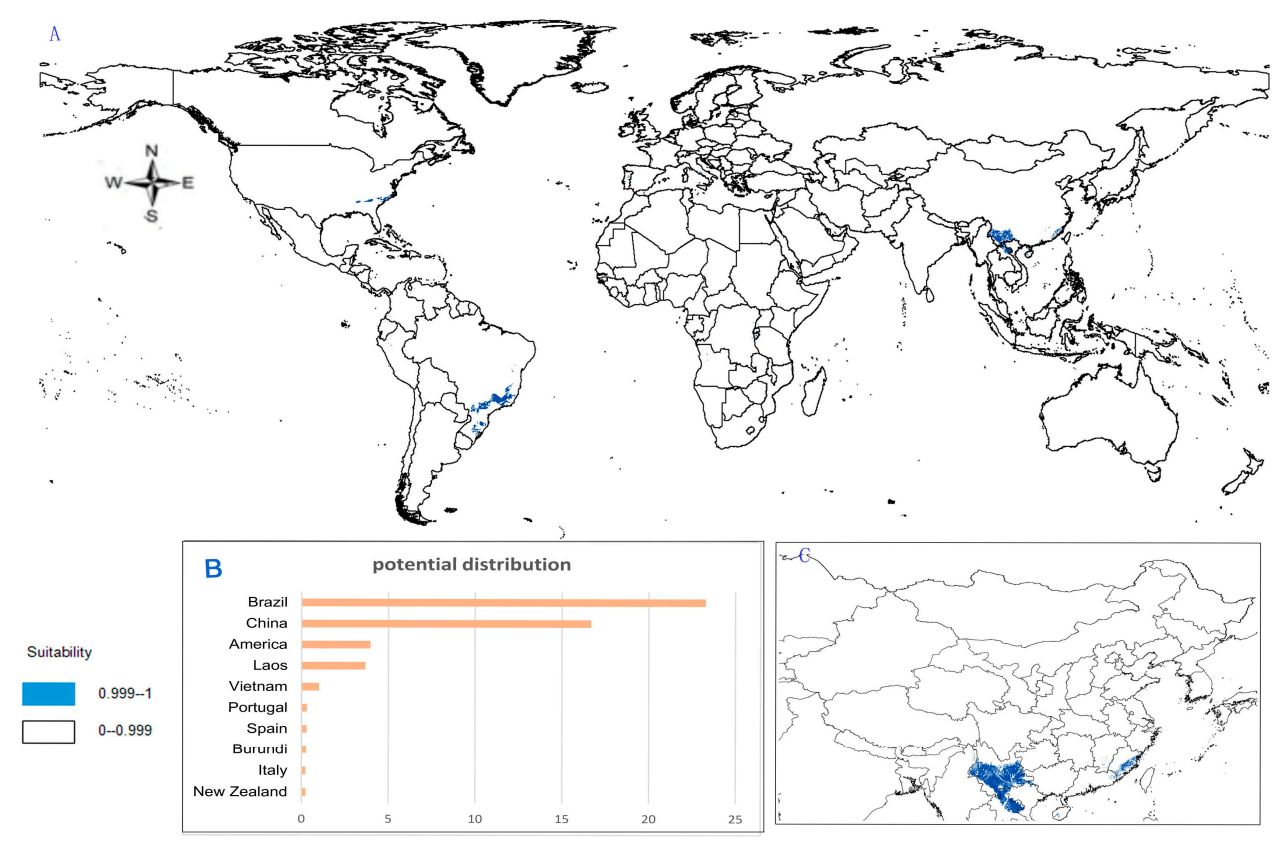

Figure 5. Spatial distribution map of potential suitable distribution for P. zingiberensis by GMPGIS. (A) Global potential distribution; (B) Global rank of the potential distribution area; (C) Chinese potential distribution.

(4) Potential distribution of P. stipuleanatus: The global potential suitable distribution of this plant is limited to several countries in Asia and South America (Figure 6A), the total area is $2.05 \times 10^{5} \mathrm{~km}^{2}$. The top three distribution areas are China $\left(108.03 \times 10^{3} \mathrm{~km}^{2}\right)$, Brazil $\left(35.92 \times 10^{3} \mathrm{~km}^{2}\right)$, and Burma $\left(27.33 \times 10^{3} \mathrm{~km}^{2}\right)($ Figure $6 \mathrm{~B})$.

\subsubsection{Chinese Potential Distribution}

P. japonicus and P. japonicus var. major are mainly distributed in the middle-latitude regions of China, including Sichuan Province, Guizhou Province, Shanxi Province, Shandong Province, Hebei Province, and Yunnan Province (Figures 3C and 4C). However, the ecological adaptation areas of $P$. zingiberensis and $P$. stipuleanatus are limited and mainly distributed in Yunnan Province, Guangdong Province, and Fujian Province (Figures 5C and 6C). In addition, Panax japonicus C. A. Mey is the most widely distributed species with ecological adaptation area of $2986.11 \times 10^{3} \mathrm{~km}^{2}$ in China. 


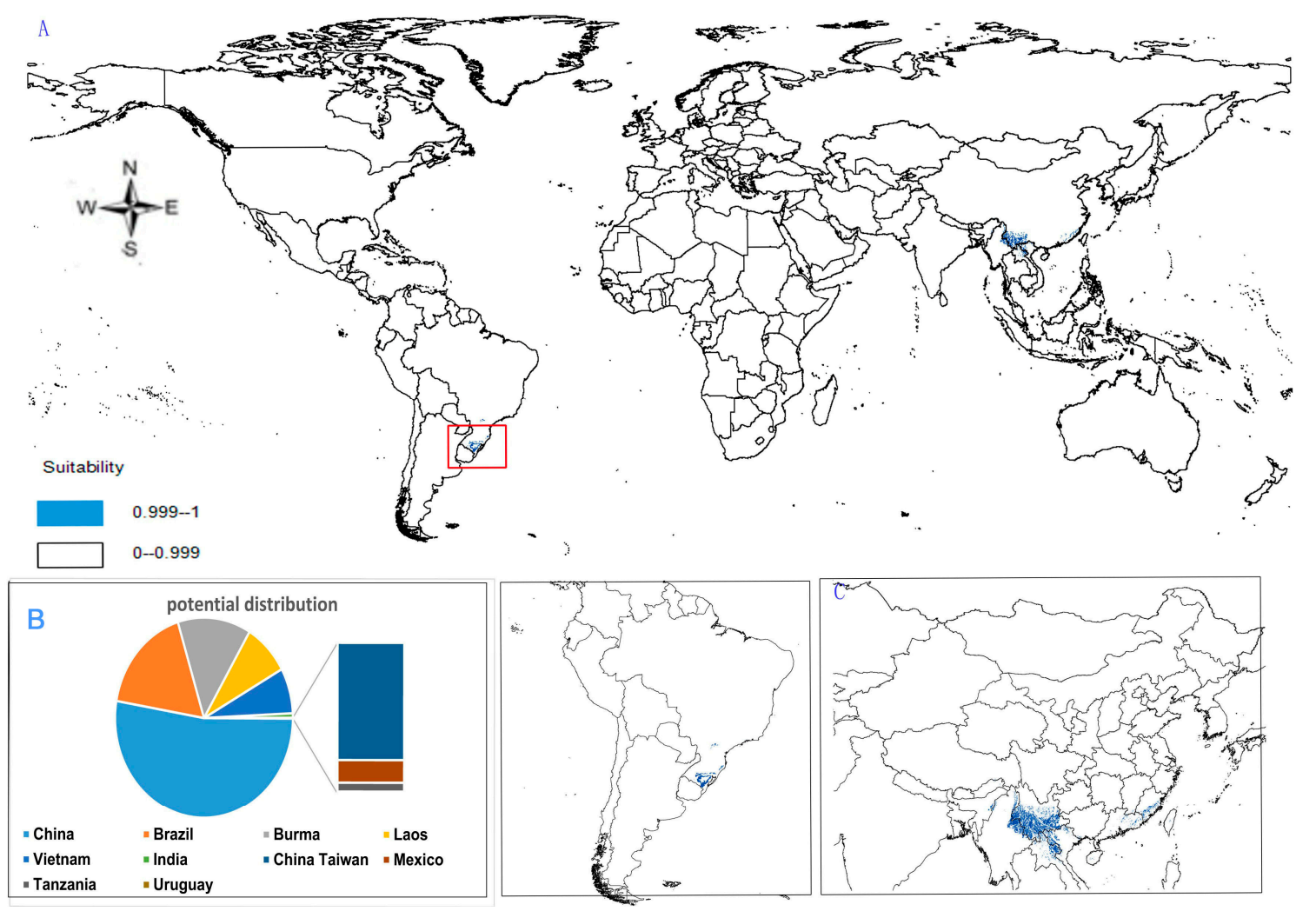

Figure 6. Spatial distribution map of potential suitable distribution for P. stipuleanatus by GMPGIS. (A) Global potential distribution; (B) Global rank of the potential distribution area; (C) Chinese potential distribution.

\section{Discussion}

\subsection{Impact of Environmental Variables on Medicinal Plants}

As shown in Table 1, different plants need different climates and habitats for their growth. The climatic factors of an actual area were simulated to provide a scientific basis for the cultivation of high-quality plants. The simulation was conducted to avoid blind introduction and reduced the workload. And we found that the mean temperature of the coldest quarter is the most important factor for these plants according to environment variable contributions (Table 3). Annual precipitation is also important for P. zingiberensis and P. stipuleanatus, Panax japonicas, annual average radiation is important for Panax japonicus var. major. Four endangered plants need suitable levels of humidity and rainfall. However, P. stipuleanatus requires a relatively low mean temperature of the coldest quarter, annual radiation, and high humidity, which are conditions found in damp habitats.

Panax species are ecologically fragile plants and sensitive to ecological factors. Due to excessive harvesting and lack of environmental protection, their natural distribution is limited. Previous studies on the relationship between plant quality and ecological factors indicate that temperature is the important ecological factor [29], similarities or differences in ecological factors lead to different metabolic contents and thus different effects. The metabolic contents of plants are affected by its habitat [30], and related research shows that lower temperature may lead to higher accumulation of ginsenosides in a certain scope of temperature for Panax species [31,32]. The present study shows that temperature is one of the important ecological factors, and the mean temperature of the coldest quarter is most important for these Panax species. The Light affects photosynthesis, changes the temperature, and affects the normal development of plants [33]. Rainfall influences humidity and other ecological 
factors [34]. The results of the previous study show a strong correlation between ecological factors and cultivation [35], in addition, all ecological factors interact with each other and are not isolated [36].

\subsection{Distribution of Suitable Habitats}

In this research, the suitable distribution areas of four plants were mapped based on the ecological factors. The suitable distribution areas of P. japonicus and P. japonicus var. major are mainly located in subtropical monsoon climate areas in China, followed by tropical monsoon climate zones, such as Sichuan Province, Guizhou Province, Shanxi Province, Shandong Province, Hebei Province, and Yunnan Province (Figures $3 \mathrm{C}$ and $4 \mathrm{C}$ ). However, some research shows that P. japonicus var. major distributed in the eastern Himalayas to western mountains in China, $P$. japonicus is the most widely distributed plant in China [37]. The suitable distribution of this study covers the above areas, and its potential suitability areas are mainly located north of Yangtze River, which mainly runs southwest to northeast across the province. Hence, the introduction and cultivation of P. japonicus var. major and $P$. japonicus should be prioritized in the above areas to obtain high output and solve the grim problems of resources. However, P. zingiberensis and P. stipuleanatus have limited potential suitable areas and are mainly distributed in Yunnan Province, Guangdong Province, and Fujian Province. Perhaps the Panax species in middle and low latitude can't fully grow in cold areas, Panax species in high latitude are more resistant to cold.

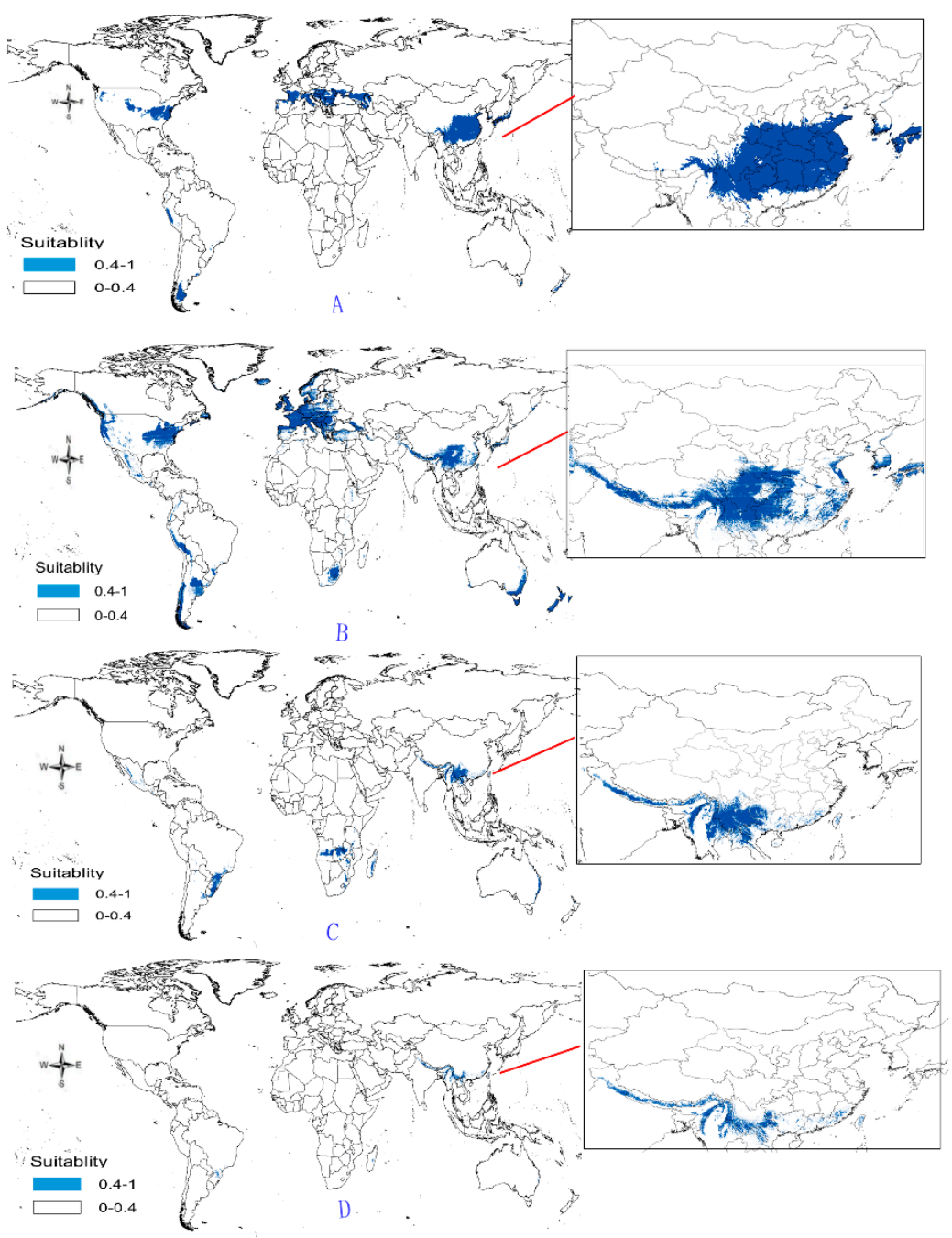

Figure 7. Spatial distribution map of potential distribution for four endangered Panax species based on MaxEnt. (A: P. japonicas; B: P. japonicus var. major; C: P. zingiberensis; D: P. stipuleanatus). 
According to the ecological adaptability map based on GMPGIS, the introduction and cultivation of P. japonicus and P. japonicus var. major may also be feasible in The United States, Italy, Spain, Brazil, and Japan. The global potential distributions are $118.29 \times 10^{5}$ and $77.5 \times 10^{5} \mathrm{~km}^{2}$ for P. japonicus var. major and P. japonicus, respectively. P. zingiberensis and P. stipuleanatus exist with global potential distributions of $5.09 \times 10^{5}$ and $2.05 \times 10^{5} \mathrm{~km}^{2}$, respectively, and may be cultivated in Brazil and Laos. This study found many undiscovered potential areas, which provide favorable conditions for the introduction of these species and play an important role in strengthening the links between China and other countries. There are some small differences, the general trend of suitable distribution by GMPGIS is similar to MaxEnt's (Figure 7), and these Panax species mainly distributed in middle and low latitudes regions. The suitable distribution only represents areas with similar environmental conditions in the sample area, but does not consider the factors of the genetic variation. Therefore, the predicted results may be deviated from the actual adaptation area of the plant. It needs to be studied in depth or be cultivated in the potential distribution to identify suitable areas for introduction and cultivation. Considerable research was conducted on Panax species for its development and utilization because its resources have received attention worldwide. With regard to unexploited wild plants, protective measures should be taken, and environmental protection should be strengthened.

\subsection{Features of GMPGIS}

We used GMPGIS to study the ecological suitability of P. ginseng, P. quinquefolium, Radix Astragali and effectively guide the production layout of the medicinal herbs [38,39]. The GMPGIS has the following festures:

(1) GMPGIS adopts the multi-index comprehensive evaluation for the quantitative and spatial analyses of the four medicinal plants.

(2) The results intuitively show the range of ecological factors and the best potential ecological areas of the plants.

(3) GMPGIS also explores the area with similar climates and soils of sampling points for medicinal plants.

(4) This system houses over 240 medicinal plants global sampling points.

(5) The model has high accuracy for medicinal plants.

The system includes ecological and environmental databases that facilitate the cultivation of medicinal plants. With the constant update and improvement of global climate database and soil data, GMPGIS technology will play an important role in the production of Chinese herbal medicine. We can intuitively understand the differences and used them to predict the distributions of medicinal plants.

\section{Methods}

Distribution sites of plants were collected from relevant literature and databases. Subsequently, their similarities were calculated after importing the latitude and longitude values from the ecological database into the GMPGIS. Finally, the global potential distribution and ecological factor values of the four endangered plants were obtained (Figure 8). The results were verified by MaxEnt.

\subsection{GMPGIS Database}

The ecological databases are important for the ecological suitability analysis. Climate data were mainly obtained from global climate data (WorldClim) and global climatologies for bioclimatic modeling (CliMond). WorldClim is recognized by the international community as a regional and accurate climate database and was established by Robert J. Hijmans [40], Susan Cameron, and Juan Parra of the Museum of Vertebrate Zoology (MVZ) , University of California, Berkeley, United States. CliMond aims to share different formats of environmental data, modeling tools, and meteorological expertise for ecological studies, such as species distribution models, species endangerment models, 
and global climate change. This database provides data such as the monthly minimum temperature, monthly maximum temperature, monthly precipitation, monthly average, 9 a.m. relative humidity, monthly average, 3 p.m. relative humidity, and 35 bioclimatic data layers.

Soil data were mainly obtained from the Harmonized World Soil Database, which is jointly formed by the United Nations Educational, Scientific, and Cultural Organization and the International Institute for Applied Systems Analysis. These institutions provide data, such as soil name, texture, effective water content, organic matter, $\mathrm{pH}$, conductivity, and other indicators. The soil types include Andosols, Acrisols, Alisols, Arenosols, Anthrosols, Chernozems, Calcisols, Cambisols, Fluvisols, Greyzems, Ferralsols, Regosols, Solonchaks, Solonetz, Gleysols, Gypsisols, Histosols, Leptosols, Kastanozems, Luvisols, Lixisols, Phaeozems, Planosols, Plinthosols, Nitisols, Podzoluvisols, Podzols, and Vertisols.

The model selected seven ecological factors, including the mean temperature of the coldest quarter, annual mean temperature, annual precipitation, annual average radiation, annual humidity, and soil type for the analysis of these plants.
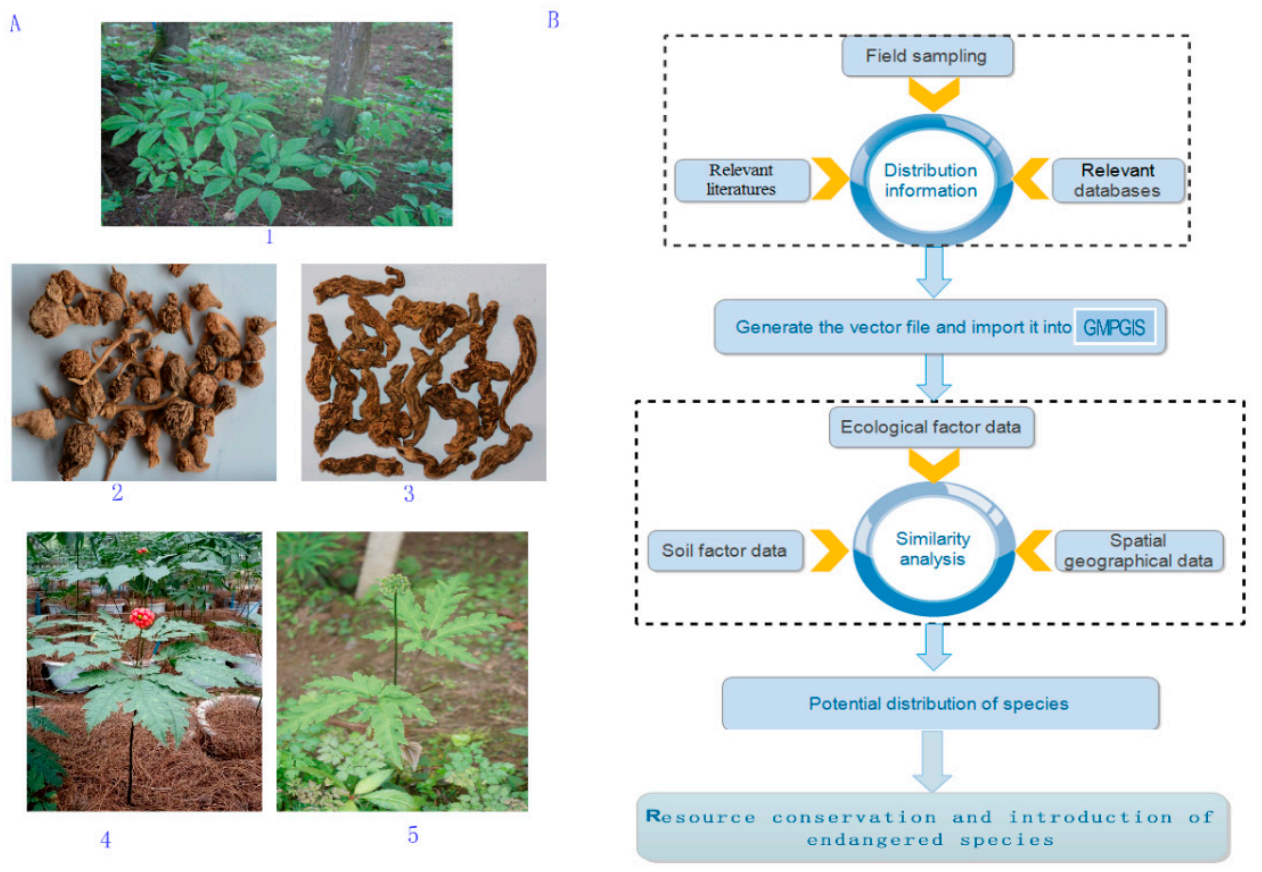

Figure 8. Picture of plant and materials (A) (1: P. japonicus, 2, 5: P. japonicus var. major, 3: P. zingiberensis, 4: P. stipuleanatus), and flow-chart of potential distribution similarity analysis (B).

\subsection{Data Collection}

Data on the distributions of P. japonicus, P. japonicus var. major, P. zingiberensis, and P. stipuleanatus were collected from our field sampling results combined with the data from the Chinese Virtual Herbarium (CVH), National Specimen Information Infrastructure (NSII), and Global Biodiversity Information Facility (GBIF). A total of 176 sampling points for P. japonicus, 274 points for P. japonicus var. major, 102 points for P. zingiberensis, and 101 points for P. stipuleanatus were collected and analyzed for the global ecological suitability.

\subsection{Principle and Algorithm of GMPGIS}

Cluster analysis is the process of partitioning a set of data points (or observations) into subsets, the k-means method is the most famous among clustering algorithms. For the original algorithm, formally, a centroid-based partitioning technique uses the centroid of a cluster $C_{i}$ to represent that cluster, where $E$ is the sum of the squared error for all points in the data set; $p$ is the point in space 
representing a given object; and conceptually, the centroid of a cluster is its center point defined as follows:

$$
E=\sum_{i=1}^{k} \sum_{p \in C_{i}} \operatorname{dist}\left(p, c_{i}\right)^{2}
$$

The GMPGIS aim to predict the distribution of medicinal plants. Firstly, to eliminate the influence of a different method, the processing of ecological factors must be standardized. Secondly, to improve the k-means, a range-based technique is adopted to evaluate the ecological suitability models and to make them more adaptable to potential distribution prediction. Thirdly, the clustering layer is reclassified, and the potential distribution of areas is discovered. Fourthly, the suitable soil layer are intersected with the climatic factors in a Euclidean distance layer. The main steps of the model by ArcGis 10.2 are as follows:

(1) Step 1: Linear normalization is performed on the original data. Suppose that $\min _{A}$ and $\max _{A}$ were the minimum and maximum values of a layer A. Linear normalization maps a value $V_{i}$ of A to $V_{i}$ in the range [newmin $A$, newmax $A$ ] by computing the following:

$$
V_{i}^{\prime}=\frac{V_{i}^{\prime}-\min _{A}}{\max _{A}-\min _{A}} \times 100
$$

(2) In our study, an improved k-means was adopted to evaluate the ecological suitability models. A range-based partitioning technique uses the critical size of a cluster $D i$ to represent that cluster. Conceptually, the critical of a cluster is its marginal value $d i$. The range can be defined in various ways, such as by the polyhedron assigned to the cluster. The difference between an object $p \in D i$ and $d i$, the representative of the cluster, is measured by dist $(p, d i)$, where dist $(x, y)$ is the Euclidean distance between two points, $x$ and $y$. The quality of cluster $D i$ can be measured by the within-cluster variation, which is the sum of the squared error between all points in $D i$ and the range $d i$, defined as follows:

$$
E=\sum_{i=1}^{k} \sum_{p \in D_{i}} \operatorname{dist}\left(p, d_{i}\right)^{2}
$$

where

$$
\operatorname{dist}\left(p, d_{i}\right)=\operatorname{IF}\left[\min \leq v_{i} \leq \max , 0, \min \left(\mid v_{i}^{\prime}-\text { newmin }_{A}|,| v_{i}^{\prime}-\text { newmin }_{A} \mid\right]\right.
$$

where $E$ is the sum of the squared error for all points in the data set, $p$ is the point in space representing a given object, and $d i$ is the range of cluster $D i$ (both $p$ and $d i$ were multidimensional). newmin $_{A}$ is the minimum value after standardizing the layer; newmax $x_{A}$ is the maximum value after standardizing the layer.

(3) According to the results of the distance calculation $\left[\mathrm{Min}_{d}, \mathrm{Max} d\right.$, the grid was classified, and the most similar ecological area was discovered.

(4) The suitable soil layer and climatic factors in the Euclidean distance layer were intersected.

\subsection{Analysis by MaxEnt}

The data of sampling points and environment variables were imported into the MaxEnt software. Parameter settings were as follows: the training set is $75 \%$ of the sampling point data, the test set is the remaining $25 \%$ used to examine the predictive ability of the model, and the jackknife was used to test the weight. The threshold-independent receiver operating characteristic and area under the receiver operating characteristic curve values were calculated by MaxEnt. The results were analyzed by ArcGIS 10.2, and the maps of ecologically suitable regions for endangered plants were obtained based on the main ecological factors. 


\section{Conclusions}

The growth of endangered medicinal plants requires appropriate ecological conditions. Their quality are closely related to ecological factors such as climate and soil. The suitability distribution analysis of medicinal plants has been based on the traditional experience, single ecological factor, and single origin studies. Therefore, traditional analysis shows low efficiency and poor accuracy. GMPGIS can combine the attributed and graphic data with powerful spatial data management, analysis and mapping ability. The prediction of potential suitable distributions is conducive to the conservation of biological diversity. The results of the present analysis include output maps, charts, and other forms, which reduce the statistical and mapping work, and achieve the visualization of regionalization for these Panax species. Hidden information can be revealed by the suitability analysis of producing areas from the geographic information system for Chinese traditional medicines. This study greatly improves the management level and application value of the resource information for traditional Chinese medicines, and provides a reference for resource conservation, introduction, and cultivation of endangered Panax species. This study is just for protection of the species, and the scientific research, it is not open to other harmful behavior.

Acknowledgments: The work was supported by grants from the National Natural Science Foundation of China (No. 81473315, No.81274013), CAMS Innovation Fund for Medical Sciences (CIFMS) (No. 2016-I2M-3-015). The Key Projects in the National Science and Technology Pillar Program (NO. 2011BAI07B08).

Author Contributions: Linfang Huang, Zhixia Du conceived and Jie Wu designed the study. Zhixia Du and Jie Wu processed the data, performed the analyses and analyzed the results, and wrote the manuscript. Linfang Huang, Zhixia Du, Jie Wu, Xiangxiao Meng, and Jinhua Li edited the manuscript. All authors read and approved the final version of the manuscript.

Conflicts of Interest: The authors declare no conflict of interest.

\section{References}

1. Yang, X.; Wang, R.; Zhang, S.; Zhu, W.; Tang, J.; Liu, J.; Chen, P.; Zhang, D.; Ye, W.; Zheng, Y. Polysaccharides from Panax japonicus C.A. Meyer and their antioxidant activities. Carbohydr. Polym. 2014, 101, 386-391. [CrossRef] [PubMed]

2. Rai, A.; Yamazaki, M.; Takahashi, H.; Nakamura, M.; Kojoma, M.; Suzuki, H.; Saito, K. RNA-seq Transcriptome Analysis of Panax japonicus, and Its Comparison with Other Panax Species to Identify Potential Genes Involved in the Saponins Biosynthesis. Front. Plant Sci. 2016, 7, e0144. [CrossRef] [PubMed]

3. Zhang, S.; Wang, R.; Zeng, W.; Zhu, W.; Zhang, X.; Wu, C.; Song, J.; Zheng, Y.; Chen, P. Resource investigation of traditional medicinal plant Panax japonicus (T. Nees) C.A. Mey and its varieties in China. J. Ethnopharmacol. 2015, 166, 79-85. [CrossRef] [PubMed]

4. Shi, F.X.; Li, M.R.; Li, Y.L.; Jiang, P.; Zhang, C.; Pan, Y.Z.; Liu, B.; Xiao, H.X.; Li, L.F. The impacts of polyploidy, geographic and ecological isolations on the diversification of Panax (Araliaceae). BMC Plant Biol. 2015, 15, 1-11. [CrossRef] [PubMed]

5. Liu, J.; Liu, Y.; Wang, Y.; Abozeid, A.; Zu, Y.G.; Zhang, X.N.; Tang, Z.H. GC-MS Metabolomic Analysis to Reveal the Metabolites and Biological Pathways Involved in the Developmental Stages and Tissue Response of Panax ginseng. Molecules 2017, 22, 496. [CrossRef] [PubMed]

6. Liu, Z.; Wang, C.Z.; Zhu, X.Y.; Wan, J.Y.; Zhang, J.; Li, W.; Ruan, C.C.; Yuan, C.S. Dynamic Changes in Neutral and Acidic Ginsenosides with Different Cultivation Ages and Harvest Seasons: Identification of Chemical Characteristics for Panax ginseng Quality Control. Molecules 2017, 22, 734. [CrossRef] [PubMed]

7. Xia, P.; Bai, Z.; Liang, T.; Yang, D.; Liang, Z.; Yan, X.; Liu, Y. High-performance liquid chromatography based chemical fingerprint analysis and chemometric approaches for the identification and distinction of three endangered Panax plants in Southeast Asia. J. Sep. Sci. 2016, 39, 3880-3888. [CrossRef] [PubMed]

8. Pimm, S.L.; Jenkins, C.N.; Abell, R.; Brooks, T.M.; Gittleman, J.L.; Joppa, L.N.; Raven, P.H.; Roberts, C.M.; Sexton, J.O. The biodiversity of species and their rates of extinction, distribution, and protection. Science 2014, 344, 1246752. [CrossRef] [PubMed]

9. Herrick, K.A.; Huettmann, F.; Lindgren, M.A. A global model of avian influenza prediction in wild birds: The importance of northern regions. Vet. Res. 2017, 44, 42. [CrossRef] [PubMed] 
10. Han, X.S.; Guo, Y.M.; Mi, C.R.; Huettmann, F. Machine Learning Model Analysis of Breeding Habitats for the Blacknecked Crane in Central AsianUplands under Anthropogenic Pressures. Sci. Rep. 2017, 7, 6144. [CrossRef]

11. Mi, C.R.; Zu, Q.; He, L. Climate change would enlarge suitable planting areas of sugarcanes in China. Int. J. Plant Prod. 2017, 11, 151-166.

12. Jiao, S.G.; Huettmann, F.; Guo, Y.; Li, X.; Ouyang, Y. Advanced long-term birdbanding and climate data mining in spring confirm passerine population declines forhe Northeast Chinese-Russian flyway. Glob. Planet. Chang. 2016, 144, 17-33. [CrossRef]

13. Guo, Y.M.; Huettmann, F.; Guo, Y.; Li, X.; Ouyang, Y. Climate envelope predictions indicatean enlarged suitable wintering distribution for Great Bustards (Otis tarda dybowski) in China for the 21st century. Peerj 2016, 4, e1630. [CrossRef]

14. Warren, D.L.; Seifert, S.N. Ecological niche modeling in Maxent: The importance of model complexity and the performance of model selection criteria. Ecol. Appl. A Publ. Ecol. Soc. Am. 2011, 21, 335-342. [CrossRef]

15. Mi, C. Why choose Random Forest to predict rare species distribution with few samples in large undersampled areas? Three Asian crane species models provide supporting evidence. Peerj 2017, 5, e2849. [CrossRef] [PubMed]

16. Kalkvik, H.M.; Parkinson, C.L. Investigating niche and lineage diversification in widely distributed taxa: Phylogeography and ecological niche modeling of the Peromyscus maniculatus species group. Ecography 2012, 35, 54-64. [CrossRef]

17. Meng, X.X.; Huang, L.F.; Dong, L.L.; Li, X.-W.; Wei, F.G.; Chen, Z.J.; Wu, J.J.; Sun, C.Z.; Yu, Y.-Q.; Chen, S.L. Analysis of global ecology of Panax notoginseng in suitability and quality. Acta Pharm. Sin. 2016, 51, 1483-1493.

18. Shen, L.; Wu, J.J.; Li, X.-W.; Xu, J.; Dong, L.L.; Sang, M.C.; Sun, C.Z.; Fujihara, N.; Chen, S.L. A study of global ecological adaptability and field selection practices of Panax ginseng. China J. Chin. Mater. Med. 2016, 41, 3314-3322.

19. Sánchez-Fernández, D.; Lobo, J.M. Species distribution models that do not incorporate global data misrepresent potential distributions: A case study using Iberian diving beetles. Divers. Distrib. 2015, 17, 163-171. [CrossRef]

20. Nag, C.; Chetan, N.; Karanth, K.P.; Praveen, K.K.; Gururaja, K.V.; Vasudeva, G.K. Delineating ecological boundaries of Hanuman langur species complex in peninsular India using MaxEnt modeling approach. PLoS ONE 2014, 9, e87804. [CrossRef]

21. Qin, Z; Zhang, J.E.; Ditommaso, A.; Wang, R.L.; Wu, R.S. Predicting invasions of Wedelia trilobata (L.) Hitchc. With Maxent and GARP models. J. Plant Res. 2015, 128, 673-755. [CrossRef] [PubMed]

22. Williams, H.W.; Cross, D.E.; Crump, H.L.; Drost, C.J.; Thomas, C.J. Climate suitability for European ticks: Assessing species distribution models against null models and projection under AR5 climate. Parasites Vectors 2015, 8, 1-15. [CrossRef] [PubMed]

23. Gormley, A.M.; Woodford, L. Using presence-only and presence-absence data to estimate the current and potential distributions of established invasive species. J. Appl. Ecol. 2011, 48, 25-34. [CrossRef] [PubMed]

24. Anderson, R.P. A framework for using niche models to estimate impacts of climate change on species distributions. Ann. N. Y. Acad. Sci. 2013, 1297, 8-28. [CrossRef] [PubMed]

25. Guisan, A.; Tingley, R.; Baumgartner, J.B.; Naujokaitislewis, I.; Sutcliffe, P.R.; Tulloch, A.I.; Regan, T.J.; Brotons, L.; Mcdonaldmadden, E.; Mantykapringle, C. Predicting species distributions for conservation decisions. Ecol. Lett. 2013, 16, 1424-1435. [CrossRef] [PubMed]

26. Folmer, E.O.; Olff, H.; Piersma, T. How well do food distributions predict spatial distributions of shorebirds with different degrees of self-organization? J. Anim. Ecol. 2010, 79, 747-756. [CrossRef] [PubMed]

27. Moat, J.; Williams, J.; Baena, S.; Wilkinson, T.; Gole, T.W.; Challa, Z.K.; Demissew, S.; Davis, A.P. Resilience potential of the Ethiopian coffee sector under climate change. Nat. Plants 2017, 3, 17081. [CrossRef] [PubMed]

28. Elith, J.; Phillips, S.J.; Hastie, T.; Dudík, M.; Chee, Y.E.; Yates, C.J. A statistical explanation of MaxEnt for ecologists. Divers. Distrib. 2011, 17, 43-57. [CrossRef]

29. Wang, E.H.; Liu, S.L.; Song, Z. Study Progression about Medicinal Plant Cold-resistance of Physiological. Chin. Agric. Sci. Bull. 2014, 30, 79-84.

30. Hou, Y.; Ma, Y.; Zou, L.S. The Effcts of ecological factors on the secondary metabolites in medicinal plants and their research methods. Lishizhen Med. Mater. Med. Res. 2015, 26, 187-190.

31. Xie, C.X.; Suo, F.M.; Jia, G.L. Correlation between ecological factors and ginsenosides. Acta Ecol. Sin. 2011, $31,7551-7553$. 
32. Jia, G.-L.; Huang, L.-F.; Suo, F.-M. Correlation between ginsenoside contents in Panax ginseng roots and ecological factors, and ecological division of ginseng plantation in China. Chin. J. Plant Ecol. 2012, 36, 302-312.

33. Han, Z.M.; Zhao, S.J.; Liu, C.J. Effects of shading on growth and quality of triennial Clematis manshurica Rupr. Acta Ecol. Sin. 2011, 31, 6005-6012.

34. Zuang, W.J.; Yu, R.C.; Zhou, T.J. Spatial Distribution and Temporal Variation of Soil Moisture over China Part II: The Evaluations for Coupled Models' Simulations. Chin. J. Atmos. Sci. 2008, 32, 1128-1146.

35. Lu, S.P.; Sui, X.-X.; Sun, Q. Biological Functions of Secondary Metabolism of Medicinal Plants and Influences of Ecological Environment. Nat. Prod. Res. Dev. 2006, 18, 1027-1032.

36. Ma, R.-J.; Jiang, Z.-G. Impact of global climate change on wildlife. Acta Ecol. Sin. 2005, 25, 3061-3066.

37. Zou, H.Y.; Zhou, D.; Zhao, H. Determination of Chikusetsusaponin V and IV a in Panax Japonicus by RP-HPLC. J. Liaoning Univ. Tradit. Chin. Med. 2015, 17, 52-54.

38. Wu, J.; Tang, H.; Huang, L.F. Research and analysis of globally ecological suitability for Taxus plants. Acta Pharm. Sin. 2017, 52, 1186-1195.

39. Chen, S.L.; Xiang, L.; Li, L.; Lan, W.U.; Huang, L.F.; Dong, Z.; Peng, S. Global strategy and raw material production on artemisinin resources regeneration (in Chinese). Chin. Sci. Bull. 2017, 62, 1982-1996. [CrossRef]

40. Hijmans, R.; Cameron, S.; Parra, J.L.; Jones, P.G.; Andy, J. Very high resolution interpolation climate surfaces for global lant areas. Int. J. Climatol. 2005, 25, 1965-1978. [CrossRef]

Sample Availability: Samples of the compounds are not available from the authors.

(C) 2017 by the authors. Licensee MDPI, Basel, Switzerland. This article is an open access article distributed under the terms and conditions of the Creative Commons Attribution (CC BY) license (http://creativecommons.org/licenses/by/4.0/). 